\title{
Interações dialógicas na experimentação investigativa em um clube de ciências: proposição de instrumento de análise metacognitivo
}

Dialogical interactions in the investigative experimentation in a club of sciences: proposition of instrument of metacognitive analysis

Carlos José Trindade da Rocha ${ }^{1}$

João Manoel da Silva Malheiro ${ }^{2}$

\section{Resumo}

Este artigo objetiva apresentar proposições de instrumento de análise com potencial metacognitivo centrado em interações discursivas por meio de atividades experimentais investigativas em um Clube de Ciências. A proposta se articula com as ações experimentais investigativas do Clube como comunidade com postura investigativa em sua abordagem didática (sete passos). A metodologia de abordagem qualitativa concebe as novas tendências de metodologias ativas, para o desenvolvimento de práticas epistêmicas com formas interativas mais gerais do processo discursivo baseadas na metacognição. A tal efeito, o instrumento possibilita aplicação de análise e intervenção pedagógica em sequências de ensino investigativa (SEI), através da resolução de problemas. A execução de proposição intenciona o trabalho de maneira interativa e colaborativa, a fim de tentar analisar o entendimento da complexa dinâmica envolvendo os processos interativos dialógicos que têm motivado o desenvolvimento de pesquisas relacionadas ao discurso entre professores e alunos, e seu impacto na condução de argumentações no contexto do ensino de Ciências.

Palavras chave: metacognição; interações discursivas; experimentação; clube de ciências

\section{Abstract}

This article aims to present propositions of analysis instrument with metacognitive potential focused on discursive interactions through experimental investigative activities in a Science Club. The proposal is articulated with the experimental investigative actions of the Club as a community with investigative stance in its didactic approach (seven steps). The qualitative approach conceives new trends in active methodologies for the development of epistemic practices with more general interactive forms of the discursive process based on metacognition. To this end, the instrument makes possible the application of analysis and pedagogical intervention in Inquiry based Teaching sequences (IBTS), through problem solving. The proposition execution intends the work in an interactive and collaborative way,

\footnotetext{
${ }^{1}$ Universidade Federal do Pará | carlosjtr@hotmail.com

2 Universidade Federal do Pará | joaomalheiro123@gmail.com
} 
in order to try to analyze the understanding of the complex dynamics involving dialogic interactive processes that has motivated the development of research related to the discourse between teachers and students, and its impact in the conduction of arguments in the context of science education.

Keywords: metacognition; discursive interactions; experimentation; science club

\section{Introdução}

Estudos tem sugerido que é por meio do debate entre os pares que, muitas vezes, os conhecimentos científicos são organizados (SASSERON, 2013; ALTARUGIO; DINIZ; LOCATELLI, 2010). Ocasiões em que se passam conversas são "momentos únicos para a troca de ideias e fundamentação do que se pretende enunciar" (p. 43).

Desta forma, em sala de aula, esses debates ou interações discursivas devem ser promovidos pelo professor com alguns cuidados, para que o debate não se transforme em um monólogo. Promover interações discursivas não é tarefa fácil, pois demanda saber perguntar e saber ouvir.

A respeito do desenvolvimento metacognitivo de alunos envolvidos em situações de interações discursivas, o presente estudo se insere no esforço de ampliação dessas reflexões no domínio das Ciências, buscando contribuir para melhor eficácia desse ensino, ao propor uma ferramenta analítica que ajude a compreender melhor o potencial metacognitivo da interação dialógica em atividade experimental investigativa.

Esta proposta de construção de um instrumento de análise para estudo de interações em sala de aula se originou e foi iniciado em uma proposta de pós-doutorado articulado a trabalhos desenvolvidos no Clube de Ciências. A proposta aprovada vem se consolidando através de estudos e pesquisas desenvolvidas no próprio Clube, envolvendo a experimentação investigativa associadas às interações discursivas, que é concebida pela implementação de uma Sequência de Ensino Investigativa (SEI), através de passos propostos por Carvalho, et al. (2009).

Na SEl, a autora propõe sete passos: O professor propõe o problema; agindo sobre os objetos para ver como eles reagem; agindo sobre os objetos para obter o efeito desejado; tomando consciências de como foi produzido o efeito desejado; dando explicações causais; escrevendo e desenhando; e relacionando atividade ao cotidiano; intencionam principalmente conhecimentos procedimentais, atitudinais e comunicacionais na ação e reflexão que ocorrem durante as aulas/atividades com discussões advindas dos experimentos, desencadeando entre professor e aluno debates contextualizados.

Permeando a proposta do instrumento de análise metacognitivo, o mesmo se propõe a entender a seguinte questão: De que maneira se estabelecem interações dialógicas e a construção de esquemas argumentativos manifestados por sujeitos de pesquisa participantes de um Clube de Ciências, ao buscar soluções para um problema real, com base na experimentação investigativa?

Acreditamos que as atividades experimentais investigativas realizadas através de um Clube de Ciências, possam ser um laboratório de pesquisa para diversas vertentes de práticas epistêmicas investigativas em nível de graduação, mestrado e doutorado que, de certo modo, tem encontrado dificuldade para adentrar aos espaços das salas de aulas para investigar interações dialógicas, devido à resistência de muitos docentes a esse tipo de 
reflexão. O Clube de Ciências estará sempre disponível como um campo metacognitivo aberto para pesquisas.

Portanto, entendemos que este trabalho fornece subsídios no sentido de identificar os qualificadores presentes em interações dialógicas entre alunos e professores, especialmente com relação à compreensão da forma como organizam os seus saberes, por ocasião das perguntas e respostas envolvidas durante a resolução dos problemas, além de entender a maneira como os participantes dão sentido e se apropriam dos conhecimentos trabalhados durante atividade experimental investigativa em Clubes de Ciências.

\section{Interações dialógicas entre professores e alunos}

Referenciando a tradição de realizar pesquisas prioritariamente com a argumentação (SASSERON; DUSCHL, 2016; MUNFORD; TELES, 2015; SASSERON, 2015; SÁ 2010; DUSCHL, 1998; COMPIANI, 1996; PERELMAN; OLBRECHTS-TYTECA, 1996; BOULTER; GILBERT, 1995; KUHN, 1993) o Brasil, com sua dimensão geográfica, necessita de abordagens didáticas formativas locais de modo a potencializar espaços educativos, alimentando uma visão crítica da pesquisa, ensino e extensão.

Sendo assim, apesar de ser reconhecida a importância da metacognição no processo de aprendizagem, parece não existir ainda uma definição unívoca. Uma breve incursão pela literatura (GOMES; ALMEIDA, 2016; LOCATELLI, 2014) nos leva, de imediato, a refletir sobre dois aspectos: por um lado, a dificuldade em estabelecer a distinção entre o que é meta e o que é cognitivo e, por outro, parece gerar alguma confusão a utilização de um termo singular para um problema multifacetado (RIBEIRO, 2003).

Num primeiro momento, conforme Locatelli (2014, p. 24) é interessante considerar metacognição como um "pensar sobre o pensamento", entretanto é necessário um aprofundamento e uma visão mais ampla dessa definição. Assim, nesta proposição de investigação, no aspecto da importância da metacognição para aprendizagem ao domínio educacional consideramos duas formas essenciais de entendimento da metacognição: 1) Conhecimento sobre o conhecimento (tomada de consciência dos processos e das competências necessárias para a realização da tarefa) e 2) controle ou auto-regulação (capacidade para avaliar a execução da tarefa e fazer correções quando necessário controle da atividade cognitiva, da responsabilidade dos processos executivos centrais que avaliam e orientam as operações cognitivas).

Nessa perspectiva, para tentar compreender as interações que ocorrem entre professores e alunos, destacamos Monteiro e Teixeira (2004) e Compiani (1996), que analisam interações gerais do processo discursivo em sala de aula, elaborando categorias (Quadro 1) que, permitem compreender melhor o papel da fala dos alunos e do professor. São identificadas como: solicitação de informações, fornecimento de informações, reespelhamento, problematização, reestruturação e recondução.

De acordo com os autores, quando não há clareza nas ideias expostas, e quando não houver discussão que explicitem um determinado fato, o fornecimento de informações se dá por intermédio de pistas na exposição direta de ideias, o que define a atitude do professor em oferecer elementos para o raciocínio do aluno, possibilitando conduzi-lo à resolução de um problema. 
Quadro 1: Categorias interativas dialógicas

\begin{tabular}{|c|c|}
\hline $\begin{array}{c}\text { CATEGORIAS } \\
\text { INTERATIVAS DIÁLOGICAS }\end{array}$ & CARACTERÍSTICAS \\
\hline Solicitação de informações & $\begin{array}{c}\text { Necessidade que apresentam os atores do processo interativo } \\
\text { em obter explicações ou esclarecimentos, interferindo } \\
\text { decisivamente nos rumos do diálogo. }\end{array}$ \\
\hline Fornecimento de informações & $\begin{array}{l}\text { Ação indutiva do professor sobre a linha de raciocínio dos } \\
\text { alunos. }\end{array}$ \\
\hline Reespelhamento & Postura adotada pelo professor para encorajar a fala do aluno. \\
\hline Problematização & $\begin{array}{c}\text { Indica uma atitude intencional, comumente do professor, mas } \\
\text { que pode partir também do aluno, de investigar, estudar, } \\
\text { provocar reflexões em busca de respostas para determinado } \\
\text { problema. }\end{array}$ \\
\hline Reestruturação & $\begin{array}{l}\text { Atitude de reorganização das proposições feitas durante as } \\
\text { interações discursivas, constituindo-se como sistematização } \\
\text { final ou parcial de ideias que foram discutidas sobre um } \\
\text { determinado assunto. }\end{array}$ \\
\hline Recondução & $\begin{array}{c}\text { Retomada, por parte do professor, da pertinência das } \\
\text { discussões que se estabelecem em sala de aula. }\end{array}$ \\
\hline
\end{tabular}

Fonte: (Monteiro; Teixeira, 2004; Compiani, 1996). Adaptado.

Ainda se destaca o remodelamento de informações entre a exposição direta e o fornecimento de pistas. No remodelamento, o professor chama atenção para pontos de vista manifestados pelos alunos, pela falta de maior precisão e detalhes; oferece informações conceituais aos alunos, dando nitidez e precisão a uma ideia, mais próximas da visão científica. O professor, durante o reespelhamento, investido de autoridade discursiva repete ou gesticula favoravelmente, o que contribui para legitimidade à ideia do aluno.

$\mathrm{Na}$ categoria problematização, os autores incluem as ideias contrapostas, que objetivam ressaltar alguma contradição ou provocar conflitos importantes para a integralização da aula. Já na reestruturação se tem a sistematização final, em que aparece uma recapitulação a fim de generalizar ideias para encerrar a questão.

A recondução destaca a dimensão de pertinência que possibilita ao professor identificar os rumos dos diálogos e sua evolução dentro do objetivo proposto no estudo, podendo intervir nas discussões, caso encontre derivações não pertinentes.

Cabe ressaltar que as interações em sala de aula propõem uma classificação do dizer do professor em: argumentação retórica, socrática e dialógica (BOULTER; GILBERT, 1995). Assim, a ideia de argumentação nos tipos de falas entre professores e alunos apresentam conexões declarativas posicionadas.

Segundo a visão de Boulter e Gilbert (1995) na argumentação retórica o pensamento e a opinião dos ouvintes não são levados em consideração; apresenta uma estrutura linear onde o professor busca persuadir uma audiência receptiva a transmissão do conteúdo.

No cenário de argumentação socrática, o tipo de discurso dirigido é conduzido pelo professor, reformulando questões para obter respostas esperadas pelos alunos. $\mathrm{Na}$ argumentação dialógica o professor se propõe a construir consensos, para que os alunos possam discutir e criar questões investigativas.

Nesse padrão discursivo, quem desempenha o papel ativo nas atividades é o aluno. $\bigcirc$ centro das atenções está em suas falas, ideias e conclusões, que devem ser garantidas e provocadas pelo professor às conclusões dos alunos, fazendo-os perceber as virtudes e as 
falhas das hipóteses levantadas, propiciando, uma interação, que permita um compartilhamento de ideias a serem consideradas coletivamente. Assim, conforme Monteiro e Teixeira (2004) parecem ser convenientes caracterizar a instigação, contraposição, organização, recapitulação, recondução e fala avaliativa, que serão mais bem definidas adiante.

Neste contexto, a proposta deste trabalho se baseia em experiências bem-sucedidas de popularização e divulgação da ciência em espaços não formais de ensino (ROCHA; MALHEIRO, 2017) da Região Nordeste do Estado do Pará, envolvendo experimentações investigativas. É crescente o número de trabalhos sobre experimentação investigativa no ensino de Ciências (SEDANO; CARVALHO, 2017; SASSERON; DUSCHL, 2015; CARVALHO, 2013) que entendem que na experimentação investigativa se exige uma atividade que permita interação entre os esquemas mentais daquele que aprende com o mundo científico e com características do contexto social em que ocorre o ensino.

Destaca-se que as ações, realizadas no Clube de Ciências (MALHEIRO; ROCHA, 2017; PRÁ; TOMIO, 2014; OLIVEIRA, 2010; GONÇALVES, 1993) mostram que há formas inovadoras de se ensinar Ciências, em que a proposição de soluções de problemas, na experimentação investigativa (SILVA, et. al., 2010; CARVALHO, 2009; KELLY, 2008), são instrumentos importantes a serem utilizados pelos professores, para melhorar e tornar mais interativo 0 ensino de Ciências (MALHEIRO; FERNANDES, 2016; SILVA, 2015).

Portanto, apesar de todas as dificuldades existentes na educação brasileira, é possível criar condições para que o aluno seja capaz de argumentar (BOULTER; GILBERT, 1995) a partir de estudos da própria realidade. Os desafios são muitos e os esforços a serem feitos precisam ser continuados para conferir capacidade de transformações interativas entre professores e alunos.

\section{Clube de Ciências Prof. Dr. Cristovam Diniz e a experimentação investigativa}

O Clube de Ciências da UFPA/Campus Castanhal Prof. Dr. Cristovam Diniz (Figura 1), surgiu com o objetivo de proporcionar um espaço catalizador de educação científica, com popularização da iniciação científica infanto-juvenil, e da ação formativa inicial e continuada de professores.

No Clube se têm consciência que, apesar da literatura da área (ROCHA; MALHEIRO, 2017; SASSERON; DUSCHL, 2016; ROCHA, 2015; CARVALHO, 2013) defender um ensino de Ciências sustentado para resolução de problemas, é preciso criar um ambiente onde professores e estudantes possam compartilhar atividades colaborativas, investigando se realmente o que está posto na teoria, de fato, se concretiza na prática de forma dialógica.

Nessa concepção, o Clube de Ciências Prof. Dr. Cristovam Diniz utiliza a filosofia la Main a la Pâte3, pois considera que a educação científica deve garantir a capacidade de

\footnotetext{
${ }^{3}$ Trata-se de uma adaptação do projeto francês La Main à la Pâte, ou seja, Mão na Massa, que por sua vez é decorrente do projeto americano Hands-On. Implementado por meio de cooperação entre a Academia de Ciências da França e a Academia Brasileira de Ciências. O projeto francês contou com a participação de Georges Charpak e o projeto americano de Leon Lederman, ambos ganhadores de prêmios Nobel (SCHIEL; ORLANDI, $\mathrm{s} / \mathrm{d})$.
} 
participar e tomar decisões fundamentadas, se baseia não apenas na aquisição de conhecimentos científicos (fatos, conceitos e teorias), mas no desenvolvimento de habilidades a partir da familiarização com os procedimentos científicos, na resolução de problemas, na utilização de instrumentos, articulação entre a investigação e o desenvolvimento da expressão oral e escrita, e, por fim, na aplicação em situações reais do cotidiano.

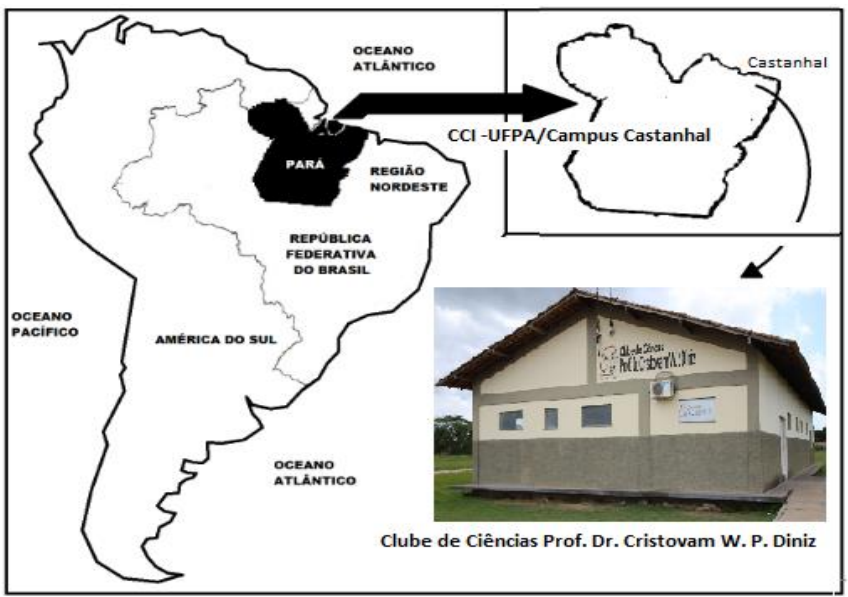

Figura 1: Localização geográfica do Clube de Ciências Prof. Dr. Cristovam W. P. Diniz.

Diante disso, o Clube busca implementar um ambiente alternativo destinado, especificamente, para o ensino, pesquisa e extensão de ações didáticas voltadas às Ciências e Matemáticas, almejando a popularização da ciência, a iniciação científica infanto-juvenil e a formação inicial e continuada de professores, e assim, apresentar aos participantes novos paradigmas educacionais (ROCHA; MALHEIRO, 2017).

Assim sendo, as atividades no Clube são voltadas para estudantes do Ensino Fundamental, mais especificamente $5^{\circ}$ e $6^{\circ}$ anos, como idades entre 9 e 15 anos, que possuam baixo rendimento escolar e que residam e estudem na área do entorno da UFPA/Campus Castanhal. Para se alcançar os objetivos pretendidos, o Clube se inspira nas concepções de ensino investigativo concebidas por Malheiro (2016) e Carvalho et al. (2009), como principal abordagem didática utilizada.

Vários aspectos importantes relativos à experimentação investigativa no ensino são abordados, levando em consideração o conteúdo programático desenvolvido nas escolas em que os alunos estudam. Destacamos que o Clube adota uma abordagem didática, que considera uma SEl em sete etapas (Figura 2). É nisso que reside o grande potencial do Clube como espaço de educação científica não formal no desenvolvimento de atividades imaginativas e criadoras. A seguir explicitamos melhor cada uma das etapas citados anteriormente.

Desta forma, as atividades experimentais investigativas buscam a solução de uma questão que será respondida pela realização de uma ou mais experiências, que podem envolver etapas ou Sequências de Ensino Investigativo (SEI).

Assim, uma SEl, deve ter algumas atividades-chave: na maioria das vezes inicia-se por um problema, experimental ou teórico, contextualizado, que introduz os alunos no tópico desejado e ofereça condições para que pensem e trabalhem com as variáveis relevantes do fenômeno científico central a ser estudado (ROCHA; MALHEIRO, 2017; CARVALHO, 2013; 
ALMEIDA, 1998) sempre motivando os conhecimentos procedimentais e atitudinais, particularmente dentro deste último, os comunicacionais.

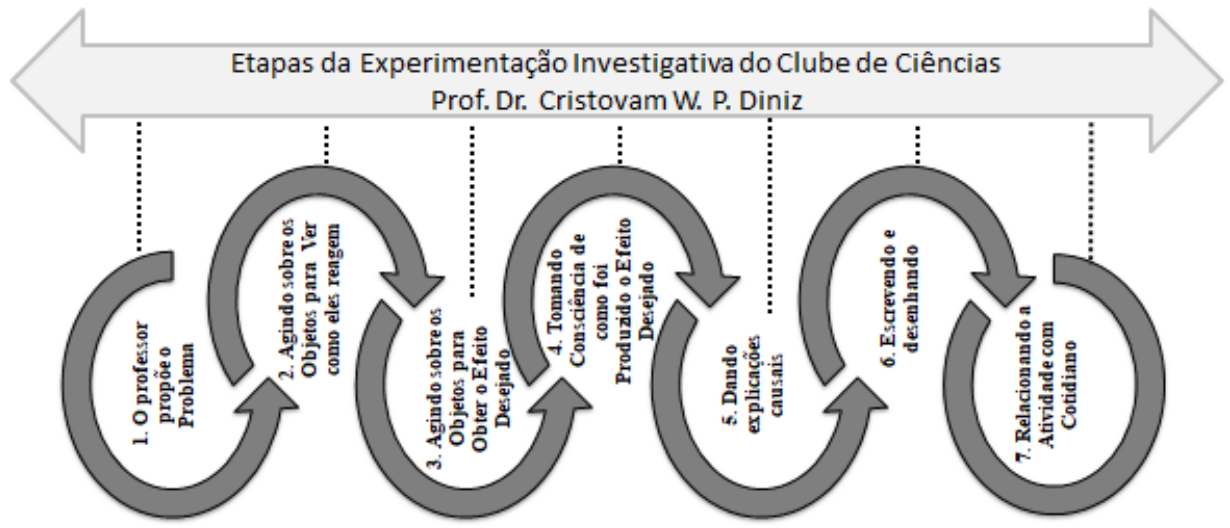

Figura 2: As sete etapas da experimentação investigativa, com base (Malheiro; Rocha, 2017).

\section{Proposição de proposta de instrumento de análise de interação dialógica}

O professor eficaz, para atuar no século XXI, deve ser reflexivo e ir muito além de dominar bem seu conteúdo e ter uma boa didática. Deverá possibilitar aulas diferenciadas que incluam abordagens didáticas, tanto cognitivas, quanto metacognitivas (LOCATELLI, 2014). Assim, possibilitar ricos momentos de aprendizagem, sobretudo a reelaboração ou a reflexão sobre ela são mágicos momentos de meta-aprendizagem, em que se pode observar um envolvimento ativo do aprendiz no processo de aprendizagem.

Desta forma, uma das partes mais importantes do processo de aprendizagem é a avaliação. Aqui, a avaliação como diagnóstico do processo é fundamental, pois a partir dela pode-se proceder à tomada de decisões para a construção e reconstrução dos conceitos que precisam ser aprimorados.

Ressalta-se que a literatura sobre o assunto (estratégias de ensino e aprendizagem) é extremamente ampla, porém estudos, apoiando-se no potencial metacognitivo da interação dialógica na experimentação investigativa, são escassos. Os estudos no Clube de Ciências mostram que as interações dialógicas, por sua organização discursiva peculiar, se constituem em interessante alternativa para fazer emergir formas de pensamento sofisticadas, como as que definem um pensamento metacognitivo crítico e reflexivo (ROCHA; MALHEIRO, 2017).

Portanto, é importante ter um instrumento de análise (Figura 3) que ajude a compreender de que maneira se estabelecem interações dialógicas e a construção de esquemas argumentativos manifestados por um grupo de professores e alunos participantes de um Clube de Ciências, ao buscar soluções para um problema real, com base na experimentação investigativa. Nossa proposta busca analisar qualitativamente processos de interações discursivas em metodologias ativas no ensino de Ciências com pressupostos metodológicos, aqui interpretados como próximos aos de uma pesquisa participante. 


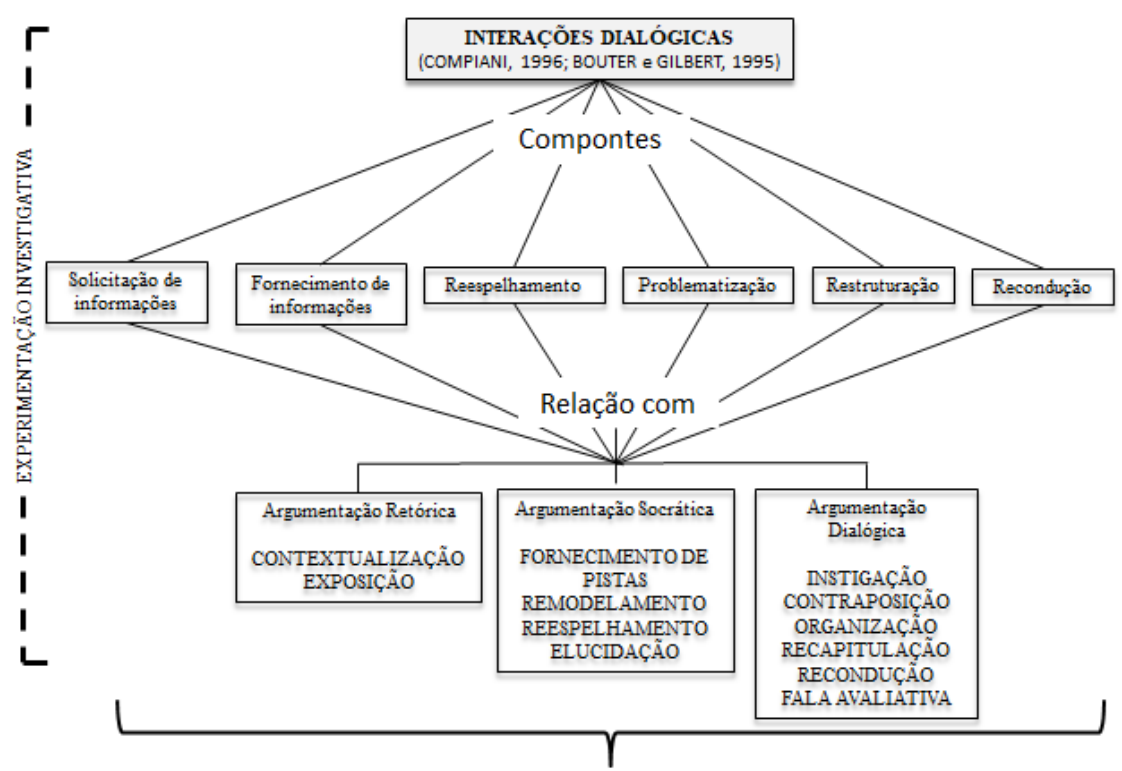

Figura 3: Plano de Análise dos dados do discurso na experimentação investigativa (Compiani, 1996; Bouter; Gilbert, 1995), adaptado.

Ao Plano de análise dos dados, inspirado principalmente nas propostas de Compiani (1996) e Bouter e Gilbert (1995), adaptamos um instrumento de análise visando propiciar um maior detalhamento das ações do professor na busca por uma construção de interações dialógicas mais refinadas e estruturadas por parte de seus alunos e, portanto, possibilitando uma compreensão de diferentes aspectos relacionados à metacognição e interação em atividades experimentais investigativas.

Conforme Monteiro e Teixeira (2004), com base em amplas interações discursivas em sala de aula, elaboram-se categorias que permitem compreender melhor o papel da fala dos alunos e do professor em sala de aula. A solicitação de informações pode ser caracterizada pela necessidade que apresentam os sujeitos interativos em alcançar explicações convincentes, intervindo de forma categórica nos rumos do diálogo. Podem ser do tipo explicação, que é solicitada quando não houver ideias que explicitem um determinado fato e clarificação, que é solicitada quando falta clareza às ideias que foram expostas.

O fornecimento de pistas define-se pela ação indutiva docente sobre o raciocínio dos alunos, feita por meio de exposição direta de ideias ou por intermédio de fornecimento de pistas, que são definidas pela atitude do professor em oferecer elementos que sustentem o aluno numa trajetória de raciocínio, previamente traçada, visando conduzi-lo à resolução de um problema. Os autores destacam ainda uma postura intermediária entre esses dois tipos de fornecimento de informações; trata-se do remodelamento.

Nesse tipo de postura, o professor chama atenção para alguns pontos de vista, apresentado pelos próprios alunos, oferecendo informações que preenchem lacunas conceituais, dando contornos sobre ideias e aproximando-a da visão científica. O reespelhamento é a postura adotada pelo professor para encorajar a fala do aluno. Investido da autoridade discursiva, o professor, ao repetir com ênfase, ou ao gesticular favoravelmente, atribui legitimidade às ideias dos alunos.

A problematização indica uma maneira propositada, normalmente do professor, mas que pode partir também do aluno, de investigar, estudar, provocar reflexões em busca de respostas para determinado problema. Nessa categoria, os autores incluem as 
contraposições, que são ideias colocadas com o objetivo de destacar alguma contradição ou gerar conflitos importantes para o desenvolvimento da aula.

A reestruturação é a atitude de reorganização das proposições feitas durante as interações discursivas, constituindo-se como organização final ou parcial das opiniões manifestadas e que foram discutidas sobre determinado assunto. Quando se têm a sistematização final, utilizada a fim de generalizar ideias para encerrar a questão, temos uma recapitulação.

A recondução caracteriza-se pela retomada, por parte do professor, da pertinência das discussões que se estabelecem em sala de aula. Monteiro e Teixeira (2004) destacam que a dimensão de pertinência permite ao docente avaliar os rumos do discurso, ou seja, admite perceber se o diálogo está evoluindo ou não dentro do objetivo principal em estudo. Ao constatar derivações não pertinentes, o professor pode intervir recolocando-o nas discussões.

Frente às categorias descritas, acredita-se que a abordagem qualitativa seja a mais adequada para esta proposição, pois propõe uma relação intrínseca com a interação estudada, permitindo que o pesquisador tenha um contato prolongado com o seu objeto de estudo, visão holística do fenômeno estudado e observe os fenômenos que influenciam o seu contexto. Essas situações são essenciais para que o pesquisador possa analisar e compreender, de forma profunda, o seu objeto de estudo.

Os acordos metacognitivos negociados através das interações dialógicas, estabelecida na SEI da experimentação investigativa, dão a possibilidade de conteúdos ou termos técnicos, já estabelecidos em língua, saírem da mera diacronização e tornarem-se objetos de sentido nos discursos. Estes acordos consideram às dicas metacognitivas propostas por Locatelli (2014), que dizem respeito à necessidade real de aprendizagem: distinguir informações relevantes das irrelevantes; conexão entre os conceitos; fazer perguntas a si mesmo o tempo todo; resumir os conceitos e formação de grupos de estudo.

Considerando a resolução de problemas é necessário saber distinguir informações relevantes das irrelevantes. Vale mencionar que, em muitos casos, para que a investigação possa trazer resultados mais consolidados do ponto de vista metacognitivo, outras perguntas podem ser feitas e associadas ao problema central (SASSERON, 2013).

A conexão entre os conceitos se recomenda para um estudo mais eficaz, concentração e atenção. É uma estratégia para o levantamento do que já se tem como alicerce para as discussões que vão ocorrer e por isso, sua importância. É um momento de tomada de consciência sobre dados à disposição.

Fazer perguntas a si mesmo todo tempo é um passo ao reconhecimento das ações realizadas. Neste momento, são reconhecidas as variáveis que atuam no fenômeno, construindo ou reconstruindo mentalmente tomadas de consciência e que são relevantes para a metacognição. Assim, recomenda-se que resuma os conceitos, para o entendimento, ao menos básico, do que está sendo estudado, monitorando o conhecimento e permitindo a regulação da aprendizagem.

Finalmente, a formação de grupos de estudo de até cinco alunos é fundamental para o desenvolvimento de diálogos. Pois, favorece que todos tenham a oportunidade de manipular materiais didáticos, construírem relações entre as variáveis, análise de condiçõeslimites de conhecimento prévios evitando dispersões.

Os componentes de interações dialógicas, ao se relacionarem com a argumentação, provocam a constituição dos aspectos de metacognição, tanto do conhecimento da 
cognição como de sua regulação. Em consequência destas relações se aproxima, sem dúvida, de um dos maiores objetivos da educação tanto básica como superior: o desenvolvimento da autonomia no estudante, conduzindo-o a saberes de como aprendem e buscando conhecimentos nos mais diversos contextos.

Não há razão em realizar atividades experimentais, quaisquer que sejam os assuntos, se estes não fizerem sentido e parte da vida dos alunos. Do que vale aprender sem apreender? De que vale significar sem ter sentido? De que vale saber por saber, pelo simples fato de mencionar? Os acordos interativos trabalhados e negociados em função de um sentido metacognitivo é que vão dar razão as argumentações retórica, socrática ou dialógica.

Percebemos então, que a metacognição vai muito além de pensar sobre o seu pensamento, ou seja, a cognição sobre a cognição. Envolve processos interativos de monitorar, avaliar e autorregular a aprendizagem (LOCATELLI, 2014). As relações estabelecidas nos processos do instrumento proposto reafirmam que a metacognição possibilita uma análise gradativa de mais metacognição, verificando as habilidades de aprender a aprender e da condução da aprendizagem.

Por meio do instrumento proposto, acreditamos que os aspectos que podem ser considerados para potencializar a metacognição ao encaminhar uma resolução para situações problemas permitem: estabelecer conceitos com significados, foco nos procedimentos de tarefas, separação de informações relevantes e irrelevantes, conexões entre fatos, fazer perguntas a si mesmo, fazer resumos, formar grupo colaborativos de estudos.

Consoante a estas reflexões, estabelecemos categorias e subcategorias de análises, inspiradas em Compiani (1996), que possibilita caracterizar, de maneira mais específica, o dizer do professor a partir das três categorias gerais (argumentação retórica, socrática e dialógica) retomando as definições que Monteiro e Teixeira (2004) e Boulter e Gilbert (1995) apresentam para cada uma dessas três categorias gerais (Figura 4).

\begin{tabular}{|c|c|c|c|c|c|c|}
\hline \multicolumn{7}{|c|}{ EXPERIMENTAÇÃO INVESTIGATIVA } \\
\hline \multicolumn{7}{|c|}{ CATEGORIZAÇÃO DO DISCURSO DO PROFESSOR } \\
\hline \multicolumn{7}{|c|}{ ARGUMENTAÇÃO RETÓRICA } \\
\hline \multicolumn{4}{|c|}{ Exposição } & \multicolumn{3}{|c|}{ Contextualização } \\
\hline \multicolumn{7}{|c|}{ ARGUMENTAÇÃO SOCRÁTICA } \\
\hline \multicolumn{2}{|c|}{ Fornecimento de pistas } & \multicolumn{2}{|c|}{ Reespelhamento } & \multicolumn{2}{|c|}{ Remodelamento } & Elucidação \\
\hline \multicolumn{7}{|c|}{ ARGUMENTAÇÃO DIALÓGICA } \\
\hline Instigação & Contr & osição & Orgar & & Recapitulação & Fala Avaliativa \\
\hline
\end{tabular}

Figura 4: Instrumento adaptado para análise dos dados (Compiani, 1996; Bouter; Gilbert, 1995), adaptado.

Estas categorias e subcategorias de análise tem como suporte instrumental qualquer tipo de mensagem e formas de expressão dos sujeitos sociais, resultando em um conhecimento não linear. Assim, essas categorias permitem compreender criticamente o sentido das falas dos sujeitos, os significados metacognitivos explícitos ou ocultos.

$\mathrm{Na}$ argumentação retórica, a exposição é o discurso docente caracterizado pela apresentação de ideias que possam subsidiar o aluno na compreensão de um determinado 
assunto. Esse encaminhamento não é desencadeado por questões propostas explicitamente pelos alunos, mas é organizado pelo professor, quando este julga que os alunos necessitam de determinadas orientações para realizar as tarefas que ele determinou. Aqui, como na contextualização, o aluno desempenha um papel passivo; é o professor que toma a iniciativa e conduz os rumos da aula (BOUTER; GILBERT, 1995).

Sendo assim, as subcategorias baseadas na argumentação socrática, podem caracterizar mais detalhadamente esse padrão discursivo do professor em sala de aula: fornecimento de pistas, reespelhamento, remodelamento, elucidação. O fornecimento de pistas, ratificando o já explicitado anteriormente, é a fala do professor que visa dirigir o raciocínio dos alunos. É feita por meio de uma explicação ou por intermédio do oferecimento de elementos que o sustentem numa trajetória de raciocínio, que possa conduzi-lo à resposta desejada ou até mesmo por intermédio de uma sucessão de perguntas que levem os alunos a determinadas conclusões (MONTEIRO; TEIXEIRA, 2004).

Reespelhamento é a fala do professor que autoriza ou não as ideias e a fala dos alunos. Investido da autoridade discursiva, o professor, ao repetir com ênfase ou mesmo gesticulando positivamente, atribui legitimidade à ideia do aluno, inibindo posições em contrário. Entretanto, a partir dessa mesma autoridade, o professor pode, com uma negativa, ou mesmo com uma espera por outras respostas, indicar para o aluno que suas ideias não foram aceitas como corretas.

Para Compiani (1996) e Bouter e Gilbert (1995), remodelamento é a fala do professor que destaca algumas ideias, apresentadas pelos alunos, que ainda carecem de maior precisão e detalhes; oferece informações que preenchem lacunas conceituais dos alunos, dando contornos precisos e nítidos a uma ideia, aproximando-a da visão científica. São ajustes feitos pelo professor a partir das ideias construídas pelos alunos.

Elucidação é a fala do professor motivada por questões colocadas pelos alunos; tem por objetivo tornar clara algumas ideias que foram expostas, mas não foram inteligíveis para alguns estudantes.

Finalmente, Bouter e Gilbert (1995) categorizam a fala do professor a partir de um terceiro tipo de discurso docente. Para esses autores, a categoria argumentação dialógica destaca-se como sendo as atitudes do professor que incentivam e regulam o compartilhamento de ideias envolvidas no processo de ensino e de aprendizagem, a partir da confrontação de opiniões expostas por todos os envolvidos.

Assim concorda-se com Monteiro e Teixeira (2004) ser conveniente caracterizar essa categoria a partir das seguintes subcategorias: instigação, contraposição, organização, recapitulação, recondução e fala avaliativa. A instigação caracteriza-se quando o professor objetiva estimular os estudantes a apresentarem suas ideias, dando início à interação dialógica em sala de aula. Os autores concebem que a Contraposição como o momento em que, na oratória do professor, percebe-se que o mesmo dá ênfase a possíveis contradições nas ideias manifestadas pelos estudantes ou quando apresenta argumentos que possam gerar confrontação de opiniões no ambiente de sala de aula.

A Organização destaca-se quando o docente organiza ideias que emanaram das considerações postuladas pelos estudantes, objetivando a refletirem sobre a aproximação e o afastamento das ideias principais que estão em discussão, o que pode desencadear novas interações dialógicas em sala de aula. É o momento que propicia a metacognição entre as ideias colocadas na discussão. A Recapitulação surge quando o professor busca fazer uma síntese dos conteúdos que foram abordados, no sentido de provocar reflexões acerca das 
opiniões que já foram apresentadas pelos alunos. É o momento de se fazer uma síntese metacognitiva de tudo o que foi discutido, com o intuito de concluir o debate. Recondução surge quando a oratória docente busca retomar o desenvolvimento metacognitivo relativo às discussões que surgiram. A fala Avaliativa é a fala do professor pela busca da lógica utilizada pelo aluno ao fazer determinada afirmação. "Essa postura docente investiga os motivos que levaram o aluno a externar uma determinada opinião" (MONTEIRO; TEIXEIRA, 2004, p. 248).

Este procedimento e processamento da construção dos dados procura reduzir o volume amplo de informações contidas em uma interação dialógica a algumas características particulares ou categorias conceituais que permitam passar dos elementos descritivos à interpretação ou investigar a compreensão dos sujeitos no contexto experimental investigativo em que produzem metacognição.

Mediante tal procedimento de análise, os depoimentos podem ser classificados em categorias visando a uma análise fidedigna das interações entre metacognição e pensamento crítico, que emerge o próprio pensamento. As possíveis categorias estabelecidas a priori do trabalho de campo, na fase exploratória de pesquisa, exigem uma fundamentação teórica sólida sobre experimentação investigativa em espaços não formais de educação científica.

Outro aspecto relevante é o apoio da técnica de vídeo gravação, que para Carvalho (2004) tem se mostra altamente produtiva, quer nas pesquisas em que o enfoque é o professor, quer nas investigações que procuram entender como se constroem os conhecimentos científicos durante as aulas, pois a filmagem das aulas possibilita estudar 0 detalhamento do processo de interações entre professor e aluno.

Já com os instrumentos e técnicas de pesquisa viabilizada, durante as observações das atividades executadas no Clube de Ciências, por captação de imagem com aparelho smartphone e filmadora HD localizados estrategicamente no espaço de sala de aula, se permite captação de imagens difusa dos sujeitos de pesquisa.

As atividades, posteriormente, devem ser transcritas e organizadas - destacando para análise transcrições dos aspectos de interações dialógicas na experimentação investigativa. É importante salientar que a disponibilização do Termo de Consentimento Livre e Esclarecido - TCLE, a todos os participantes para autorização de gravações.

Ainda, no processo de análise utiliza-se a seleção de transcrição de falas entre professores e alunos, selecionando turnos que se aproximem dos aspectos de características das categorias propostas no discurso dos professores como unidades de análise de acordo com a análise do conteúdo (BARDIN, 2009) em fases: a pré-análise; a exploração do material; o tratamento dos resultados, a inferência e a interpretação com representação de quadros, figuras e tabela, baseando-se em espirais de reflexão e ação, que inclui aclarar e diagnosticar uma situação prática ou um problema prático que se quer melhorar ou resolver; formular estratégias de ação; desenvolver essas estratégias e avaliar sua eficiência; ampliar a compreensão de situações metacognitivas.

\section{Considerações}

As reflexões dessa pesquisa possibilitam apresentar, descrever e discutir sobre a importância promover proposições de instrumento de análise com potencial metacognitivo 
centrado em interações discursivas por meio de atividades experimentais investigativas em um Clube de Ciências.

A proposição aqui apresentada, que é adaptável e flexível a quem pesquisa esta temática, possibilita potencializar os aspectos metacognitivos explícitos ou ocultos. Acreditamos na importância da atuação de um pesquisador crítico, ético, reflexivo, criativo, dinâmico, na compreensão da realidade social e de contradições, no enfrentamento das diversas expressões da questão que envolva interações dialógicas, que se manifestam no cotidiano de ensino, com um sentido original e confiável voltado para contribuir para a construção de conhecimentos.

Associar processos de análise com triangulações de dados é o que se espera nas pesquisas com abordagem qualitativa. Nesse sentido, a seleção, adaptação ou criação de instrumentos devem priorizar a confiabilidade e validade. Não é possível confiar em uma forma de análise que não tenha clareza.

É necessário esclarecer conforme Sampiere et al. (2006), que em uma pesquisa, existem duas opções com relação ao instrumento de análise: Escolher um instrumento já desenvolvido e disponível, que se adapte às necessidades do estudo em particular e construir um novo instrumento de medição de acordo com a técnica apropriada para isso. Em ambos os casos, é importante demonstrar a confiabilidade e validade dos mesmos.

Defendemos, portanto, a necessidade de incentivos a uma arquitetura de análise metacognitivo do próprio pesquisador em sua formação sólida, voltados para alfabetização científica e com foco no trabalho com a modalidade interativa, como se busca no Clube de Ciências Prof. Dr. Cristovam Diniz.

\section{Referências}

ALMEIDA, A. M. Papel do Trabalho Experimental na Educação em Ciências. Comunicar Ciências. Ministério da Educação - Portugal. Departamento de Ensino Secundário, ano I, n. 1, 1998.

ALTARUGIO, M. H.; DINIZ, M. L.; LOCATELLI, S. W. O debate como estratégia em aulas de química. Química Nova na Escola, v.32, n.1, p. 26-30, 2010.

BARDIN, L. Análise de conteúdo. Lisboa, Portugal. Edições 70. LDA, 2009.

BOULTER, C. J.; GILBERT, J. K. Argument and science education. In: Costello, P.J. M. e Mitchell, S. (edts). Competing and Consensual voices: the theory and pratice of argument. Multilingual Matters LTD, cap.6, p. 84-98, 1995.

CARVALHO, A. M. P. O ensino de ciências e a proposição de sequências de ensino investigativas. In: CARVALHO, A. M. P. (Org.) Ensino de Ciências por Investigação: Condições para implementação em sala de aula. São Paulo: Cengage Learning, p. 1-20, 2013.

CARVAlHO, A. M. P. et al. Ciências no Ensino Fundamental: o Conhecimento Físico. São Paulo: Scipione, 2009.

CARVALHO, A. M. P. Uma Metodologia de Pesquisa para Estudar os Processos de Ensino e Aprendizagem em Salas de Aula. In: SANTOS, Flávia Maria Teixeira; GRECA, Ileana Maria 
(Orgs). A Pesquisa em Ensino de Ciências no Brasil e suas Metodologias. ljuí (RS): Ed. Unijuí, 2006.

DUSCHL, R. La valorización de argumentaciones y explicaciones: promover estratégias de retroalimentación. Enseñanza de Las Ciências, v. 16, n. 1, p.3-20, 1998.

GONÇALVES, T. V. O. Pontes entre Universidade e o $1^{\circ}$ e $2^{\circ}$ graus: de Clubes de Ciências na experiência do NPADC/UFPA. Caderno Catarinense de Ensino de Física, Florianópolis, v. 10, n.1, p. 95-99, 1993.

GOMES, A. S. A.; ALMEIDA, A. C. P. C. Letramento científico e consciência metacognitiva de grupos de professores em formação inicial e continuada: um estudo exploratório. Amazônia Revista de Educação em Ciências e Matemática, v.12, n.24, p.53-72, 2016.

KELLY, G. J. Inquiry, activity and epistemic practice. In Duschl, R. A.,e Grandy, R. E. (eds.) Teaching Scientific Inquiry: recommendations for resarch and impementation. Rotterdam, Holand: Taipei Sense Publishers, p. 288-291, 2008.

KUHN, D. Science as argument: implications for teaching and learning scientific thinking. Science Education, v.77, n.3, p. 319-337, 1993.

LOCATELLI, S. W. Tópicos de metacognição: para aprender a ensinar melhor. $1^{\mathrm{a} e d}$. Curitiba: Appris, 2014.

MALHEIRO, J. M. S; ROCHA, C. J. T. Clube de Ciências prof. Dr. Cristovam W. P. Diniz e o ensino investigativo no município de Castanhal/Pa. EnECl - Encontro de Ensino de Ciências por Investigação. Universidade de São Paulo - USP/LaPEF-FEUSP. 2017.

MALHEIRO, J. M. S; FERNANDES, P. O recurso ao trabalho experimental e investigativo: Percepções de professores de ciências. Investigações em Ensino de Ciências, v. 20, n.1, p. 79-96, 2015.

MALHEIRO, J. M. S. Atividades experimentais no ensino de ciências: limites e possibilidades. ACTIO: Docência em Ciências, v. 1, n. 1, p. 107-126, 2016.

MONTEIRO, M. A. A. e TEIXEIRA, O. P. B. Uma análise das interações dialógicas em aulas de ciências nas séries iniciais do ensino fundamental. Investigações em Ensino de Ciências. Publicação eletrônica, v.9, n.3, p. 243-263, 2004.

MUNFORD, D.; TELES, A. P. S. S. Argumentação e a construção de oportunidades de aprendizagem em auas de ciências. Ens. Pesqui. Educ. Ciênc. (Belo Horizonte) [online], v.17, n. spe, p.161-185, 2015.

OLIVEIRA, M. A. de. Alfabetização científica no clube de ciências do ensino fundamental: uma questão de inscrição. Revista Ensaio, Belo Horizonte, v.12, n. 2, p.11-25, 2010.

PERELMAN, C.; OLBRECHTS-TYTECA, L. Tratado da argumentação: a nova retórica. $2^{a}$ ed. São Paulo (SP): Martins Fontes, 1996.

PRÁ, G.; TOMIO, Clube de Ciências: Condições de produção da pesquisa em educação científica no Brasil. Alexandria, Revista de Educação em Ciência e Tecnologia, v.7, n. 1, p. 179-207, 2014. 
ROCHA, C. J. T.; ALTARUGIO, M. H.; MALHEIRO, J. M. S. Educação química e características de ensino investigativo em escolas públicas da região norte do Brasil. Educação Química Em Punto de Vista, v.1. n.1. p. 41-58, 2017.

ROCHA, C. J. T. Ensino da química na perspectiva investigativa em escolas públicas do município de Castanhal-Pará. 2015. 120f. Dissertação (Mestrado). Universidade Federal do ABC. Santo André. São Paulo.

SÁ, L. P. Estudo de casos na promoção da argumentação sobre questões sócio-científicas no Ensino Superior de Química. Tese (doutorado) Universidade Federal de São Carlos. São Carlos-SP. 2010.

SAMPIERI, R. H.; COLLADO, C. F.; LUCIO, P. B. Metodologia de pesquisa. 3. ed. São Paulo: McGraw-Hill, 2006.

SASSERON, L. H.; DUSCHL, R. A. Ensino de ciências e as práticas epistêmicas: o papel do professor e o engajamento dos estudantes. Investigação em Ensino de Ciências, v. 21, n. 2, p. 52-67, 2016

SASSERON, L. H. Interações discursivas e investigação em sala de aula: o papel do professor. In: CARVALHO, A.M.P. (Org.) Ensino de ciências por investigação: condições para implementação em sala de aula. São Paulo: Cengage Learning, 2013.

SEDANO, L.; CARVALHO, A. M. P. Ensino de ciências por investigação: oportunidades de interação social e sua importância para a construção da autonomia moral. Alexandria, R. Educ. Ci. Tec., Florianópolis, v.10, n.1, p.199-220, 2017.

SCHIEL, D.; ORLANDI, A. S. Ensino de ciências por investigação. Dietrich Schiel; Angelina Sofia Orlandi (Org.). [et al.] - São Carlos, SP: Compacta Gráfica e Editora Ltda., s/d.

SILVA, A. A. B. Interações Discursivas em um Curso de Férias: A constituição do conhecimento científico sob a perspectiva da Aprendizagem Baseada em Problemas. 89f. Dissertação (Mestrado em Educação em Ciências). Belém (PA): IEMCI/UFPA, 2015.

SILVA, R. R. da; MACHADO, P. F. L; TUNES, E. Experimentar sem medo de errar. In: Ensino de química em Foco. (Org.) SANTOS, W. L. e MALDANER, O. A., ed. Unijuí, cap. 9, p. 231261, 2010. 